\title{
Direito à educação e sistemas privados de ensino nas redes públicas: hipóteses para análise jurídica
}

\author{
Right to education and private systems of teach in public networks: \\ hypotheses for legal analysis
}

\section{Derecho a la educación y sistemas privados de enseñanza en redes públicas: hipótesis para análisis jurídico}

\author{
Salomão Barros Ximenes' \\ 'Universidade Federal do ABC - UFABC - Santo André - SP - Brasil Email: \\ salomao.ximenes@ufabc.edu.br
}

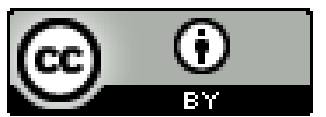

Educação: teoria e prática, Rio Claro, SP, Brasil - eISSN: 1981-8106

Está licenciada sob Licença Creative Common

\section{Resumo}

$\mathrm{O}$ artigo retoma o marco conceitual sobre o direito humano à educação desenvolvido pelo Comitê DESC da ONU, com base no qual propõe que seja analisado o impacto dos processos de privatização da educação no Brasil, mais especificamente aqueles representados pela crescente adoção de sistemas privados de ensino nas redes públicas. Nessa sistematização, de um lado evidencia que a privatização pode exacerbar e qualificar violações, principalmente quanto aos deveres de não discriminação, adaptação, gestão democrática e autonomia relativa de professores e escolas. Como resultado, oferece uma análise inicial para as questões jurídicas que poderão ser mensuradas nas pesquisas sobre o assunto.

Palavras-chave: Direito à educação. Privatização da educação. Políticas educacionais.

\begin{abstract}
The article takes up the conceptual framework on the human right to education developed by the UN ESCR Committee, based on which proposes to analyze the impact of education privatization processes in Brazil, specifically those represented by the increasing adoption of private education systems in public networks. This systematization, on the one hand shows that privatization can exacerbate and qualify violations, especially regarding the duties of non-discrimination, adaptation, democratic management and autonomy of teachers and schools. As a result, it provides an initial analysis of the legal issues that can be measured in research about this subject.
\end{abstract}

Keywords: Right to education. Privatization of education. Educational policies. 
El artículo retoma el marco conceptual sobre el derecho humano a la educación desarrollado por el Comité DESC de la ONU, basado en el que se propone analizar el impacto de los procesos de privatización de educación en Brasil, específicamente los representados por la creciente adopción de los sistemas privados de enseñanza en redes públicas. Esta sistematización, por un lado, muestra que la privatización puede exacerbar y calificar violaciones, especialmente en relación con las obligaciones de no discriminación, de adaptación, de gestión democrática y cuanto a la autonomía de los docentes y de las escuelas. Como resultado, proporciona un análisis inicial de las cuestiones jurídicas que se pueden medir en la investigación sobre el tema.

Palabras-clave: Derecho a la educación, privatización de la educación, políticas educativas.

\section{Introdução}

Ganham relevância e visibilidade, no Brasil, os estudos sobre as diferentes modalidades de privatização da educação. Esses estudos têm, como base empírica, a diversificação dos modelos de parceria público-privada, a crescente participação da educação na agenda de negócios e o acirramento das disputas sobre a destinação dos recursos públicos dos diferentes entes federados (ADRIÃO et al., 2009, 2012).

O processo legislativo que levou à aprovação do novo Plano Nacional de Educação PNE - Lei $n^{\circ} 13.005 / 2014$ - é mostra desse embate (BRASIL, 2014). Se, por um lado, a redação final da Meta 20 do PNE tem potencial de elevar significativamente os gastos públicos em educação pública, por outro lado saiu fortalecida a possibilidade de se implantar e ampliar políticas de repasse à iniciativa privada, contabilizadas dentro da meta de atingir, no mínimo, o patamar de $7 \%$ do PIB do País no $5^{\circ}$ ano de vigência da Lei e, no mínimo, o equivalente a $10 \%$ do PIB ao final do decênio, em 2024. Isso porque a Meta foi excepcionada no $\S 4^{\circ}$ do art. $5^{\circ}$ da Lei $n^{\circ} 13.005 / 2014$, autorizando-se a inclusão, no cálculo dos gastos públicos, dos recursos aplicados nos programas de expansão da educação profissional e superior, inclusive na forma de incentivo e isenção fiscal, as bolsas de estudos concedidas no Brasil e no exterior, os subsídios concedidos em programas de financiamento estudantil e o financiamento de creches, pré-escolas e de educação especial na forma do art. 213 da Constituição Federal (BRASIL, 1988).

Ao mesmo tempo em que são expandidos os programas de parceria público-privada pelas vias contempladas no art. 213 da Constituição e no $\$ 4^{\circ}$ do art. $5^{\circ}$ do PNE, são notórios outros movimentos de privatização, tais como o crescimento incentivado, via subsídios Educação: Teoria e Prática/ Rio Claro/ Vol. 25, n.50/ p. 576-592/ Set.-Dez. 2015. 
fiscais, à matrícula em instituições privadas de educação básica e a oferta de sistemas privados de ensino às redes públicas, sobretudo municipais.

Uma vez que a legislação contempla muitas dessas iniciativas, ou seja, que o Direito veio sendo moldado de forma a permitir uma crescente participação do setor privado inclusive do setor lucrativo - no financiamento público da educação, em que medida esse fenômeno poderia ser criticado sob o ponto de vista jurídico? É possível estabelecer uma análise jurídica sobre os processos de privatização da educação no Brasil, inclusive sobre as normas que viabilizam tais processos, monitorando-os quanto à realização do direito à educação?

Essas questões nos remetem à diferença entre as dimensões empírica e normativa dos estudos jurídicos, tópico essencial para a análise do Direito no constitucionalismo contemporâneo. Compartilhamos, nesse aspecto, do enfoque proposto por Robert Alexy (2008) para o estudo dos direitos fundamentais. Para esse autor, o Direito, enquanto disciplina prática, ao mesmo tempo conectada a posições morais, impõe a integração de três perspectivas da chamada dogmática jurídica: além da dogmática normativa, que tem como propósito fornecer respostas adequadas ao conteúdo de cada direito específico, há a dogmática analítica, que trata dos conceitos jurídico-políticos fundamentais e da estrutura do sistema jurídico, e a dogmática empírica, voltada ao conhecimento do direito positivo, da prática jurisdicional e de sua aplicação.

A dogmática normativa, portanto, não objetiva responder às questões sobre como a privatização vem sendo realizada na prática e como o Direito vem sendo utilizado para isso. Seu objetivo é oferecer proposições básicas sobre o conteúdo normativo de cada direito, com base nas quais passa a ser possível avaliar os processos de juridificação ${ }^{1}$ e as diferentes concepções em disputa.

Esse enfoque metodológico é que nos permite estabelecer critérios para a análise jurídica do próprio Direito que está na base das políticas públicas educacionais e das opções políticas que lhe dão fundamento. No caso, propomos o conteúdo normativo do direito humano à educação básica para que, com base nele, possibilite-se a análise de questões práticas encontradas nas pesquisas e na legislação.

\footnotetext{
${ }^{1}$ Por juridificação deve se entender "a ampliação dos temas juridificáveis nos quadros da positivação do direito". (NEVES, 2011, p. 165). Enquanto fenômeno jurídico-social, é fruto da diferenciação e da complexificação dos arranjos sociais e da consequente diferenciação e fragmentação do próprio direito. Esse fenômeno é perceptível no campo das políticas educacionais, amplamente traduzidas em formas jurídicas. Deve-se atentar para não confundir esse fenômeno geral com um de seus componentes específicos - a judicialização, fenômeno que diz respeito, diretamente, à crescente participação do sistema de justiça nas decisões que caracterizam os demais poderes do Estado.

Educação: Teoria e Prática/ Rio Claro/ Vol. 25, n.50/ p. 576-592/ Set.-Dez. 2015.
} 


\section{O conteúdo do direito à educação ante as obrigações estatais de respeitar, proteger e realizar os direitos humanos fundamentais ${ }^{2}$}

Conforme proposto em trabalho no qual se busca estabelecer um marco teórico ampliado sobre o conteúdo do direito à qualidade na educação básica, o primeiro passo para compreensão desse conteúdo é o reconhecimento de uma teoria (dogmática) geral e unitária dos direitos fundamentais (XIMENES, 2014). Conforme analisa Ximenes (2014), recorrendo a teóricos críticos de uma visão fragmentada e ideologicamente determinada (HOLMES; SUNSTEIN, 2011; ABRAMOVICH; COURTIS, 2004), todos os direitos - sejam eles civis, políticos, econômicos, sociais ou culturais - exigem do Estado três tipos de obrigação. O que vai definir o peso de cada uma dessas obrigações na realização do direito em questão, nessa teorização, não é a classificação prévia do mesmo, mas seu grau de reconhecimento legal e de implementação prática.

Essa proposição básica - radicalmente oposta às teorias hegemônicas sobre a natureza específica dos direitos sociais - foi desenvolvida durante a década de 1990, e difundida, inicialmente, na Recomendação Geral n 12, de 1999, do Comitê de Direitos Econômicos, Sociais e Culturais da ONU (Comitê DESC), sobre o direito à alimentação adequada (XIMENES, 2014). Nesse documento, o Comitê DESC desenvolve o conteúdo dos direitos humanos previstos no Pacto Internacional de Direitos Econômicos, Sociais e Culturais (PIDESC) e em outros tratados internacionais, concluindo que tais normas podem ser interpretadas a partir dos deveres que, em conjunto, impõem aos Estados. Esse deveres, ou obrigações, podem ser organizados em três tipos: respeitar, proteger e realizar, subdividindose este em duas espécies, quais sejam, os deveres de facilitar ou promover indiretamente e de prover ou prestar diretamente. A recomendação seguinte do Comitê DESC foi dedicada, especificamente, à interpretação do conteúdo do direito à educação com base no PIDESC. Nesse documento - Recomendação Geral no 13, de 1999 - o Órgão aplica a mesma teorização sobre os deveres estatais ao direito à educação. Vejamos as disposições propostas pelo Comitê:

46. O direito à educação, como todos os direitos humanos, impõe três níveis
de obrigações aos Estados-parte: as obrigações de respeitar, as obrigações de
proteger e de realizar. Por sua vez, a obrigação de realizar impõe a obrigação
de promover e a obrigação de prover diretamente.
47. A obrigação de respeitar exige que os Estados-parte evitem as medidas
que obstaculizem ou impeçam o gozo do direito à educação. A obrigação de
proteger impõe aos Estados-parte adotar medidas que impeçam que o direito
à educação seja obstaculizado por terceiros. A de realizar (facilitar) exige
que os Estados adotem medidas positivas que permitam a indivíduos e
comunidades gozar do direito à educação e lhes preste assistência. Por
último, os Estados-parte têm a obrigação de realizar (prover) o direito à

\footnotetext{
${ }^{2}$ Esse tópico e o seguinte foram desenvolvidos com base no seguinte trabalho do autor: Salomão Ximenes (2014).

Educação: Teoria e Prática/ Rio Claro/ Vol. 25, n.50/ p. 576-592/ Set.-Dez. 2015.
} 
educação. Como norma geral, os Estados-parte estão obrigados a realizar (prover) o direito específico do Pacto cada vez que um indivíduo ou grupo não pode, por razões alheias à sua vontade, pôr em prática o direito por si mesmo com os recursos à sua disposição. Não obstante, o alcance dessa obrigação está subordinado, sempre, ao texto do pacto (ONU, 1999 apud XIMENES, 2014, p. 244).

Assim, a partir da realidade constitucional brasileira, o dever de respeitar e proteger o direito à educação contempla: (i) o conjunto de liberdades educacionais (CF/88, art. 206, II) liberdade de ensino, quanto à criação e à escolha de escola privada; liberdades no ensino, envolvendo a liberdade acadêmica dos professores e dos alunos -; (ii) o pluralismo de ideias e de concepções pedagógicas (CF/88, art. 206, III), destacadamente a dimensão de autonomia relativa das escolas na definição e na implementação desse projeto e na gestão interna de seus processos; e, complementarmente, (iii) o requisito relativo à gestão democrática do ensino público $(\mathrm{CF} / 88$, art. 206, VI), que limita a atuação da administração central, abrindo espaço à participação na condução das escolas e da política educacional (BRASIL, 1988).

Esses deveres estatais, relativos ao respeito e à proteção, entretanto, estão diretamente relacionados e dependentes daqueles deveres que, comumente, caracterizam o direito educacional, ou seja, os deveres de provimento direto da educação escolar pelo Estado. O que buscamos ressaltar, contudo, é que a prevalência da dimensão prestacional, na realização do direito à educação, não nos autoriza a desconsiderar ou minimizar a importância das demais dimensões de deveres estatais.

Portanto, há dever estatal de promover diretamente a educação de qualidade, aceitável, adaptável e não discriminatória junto às instituições públicas e privadas. Ainda que estas, com base no dispositivo Constitucional, sejam livres para constituir escolas, não o são quanto ao conteúdo e aos deveres educacionais. Por outro lado, o fato de se tratar de escola pública estatal não autoriza a administração central do Estado a geri-la de forma centralizada e/ou autoritária. Assim, em relação às escolas privadas o não fazer consiste em não estabelecer requisitos excessivos para sua criação e funcionamento, ainda que os requisitos devam ser rigorosamente exigidos, por se tratar a educação de um bem público; em relação às públicas, o não fazer significa respeitar e proteger uma significativa margem de autonomia, de liberdade de ensinar e de aprender e de gestão democrática. Diferentemente das concepções puramente liberais, de um lado, ou de concepções totalitárias, de outro, o referencial normativo de direitos humanos não dá margem nem à liberdade absoluta, na educação privada, nem à falta de liberdade, na educação pública. Nesse sentido:

A ideia geral, aplicável ao conjunto dos direitos humanos e típica da concepção de responsabilidade internacional nesse campo, é que o Estado é o último e mais importante garantidor dos direitos. Daí a centralidade que o Comitê concede ao detalhamento do conteúdo normativo dos deveres estatais relativos ao direito à educação (a educação em todas as suas formas e níveis tem que estar disponível, ser acessível, aceitável e adaptável), conforme veremos logo adiante. Ainda que esse conteúdo se articule com cada uma das dimensões de obrigações estatais, sejam elas negativas ou positivas - ou seja, obrigações de respeitar ou de proteger e realizar -, é ao Estado que incumbe a atribuição final de realizar cada uma dessas 
características ou de dotar os sistemas e as instituições educacionais públicas de condições para a sua realização (XIMENES, 2014, p. 244-245).

Também, cabe ao Estado averiguar o cumprimento dos requisitos de qualidade nas instituições privadas, bem como impedir que estas venham a violar características centrais do direito, como a não discriminação e a adaptabilidade, detalhadas adiante.

Este princípio geral sobre a precedência dos deveres estatais quanto à garantia do direito à educação é fortalecido no modelo jurídico-constitucional brasileiro, que reconhece deveres estatais amplos (CF/88, arts. 208, 211 e 212), ainda que também reconheça a participação da iniciativa privada na oferta educacional, inclusive com possibilidade de acesso a recursos públicos (CF/88, arts. 209 e 213) (BRASIL, 1988).

Portanto, a Recomendação nº 13, de 1999, do Comitê DESC é uma referência teórica e prática imprescindível para a construção de uma proposta analítica sobre a realização do direito à educação nos diferentes contextos, que responde à necessidade de se tomar como referência um conteúdo normativo não limitado ao mero dever de oferta de vagas em número suficiente. Nela, o Comitê estipula quatro dimensões necessárias para o direito universal à educação, em relação às quais são aplicáveis cada um dos tipos de deveres estatais de respeito, proteção e realização. Essas dimensões são: disponibilidade, acessibilidade, aceitabilidade e adaptabilidade.

\section{As quatro dimensões necessárias do direito à educação}

Essas características fundamentais do direito à educação, tributárias do desenvolvimento teórico originalmente proposto por Tomasevski (2001), podem ser compreendidas, didaticamente, a partir de quatro níveis de realização do direito à educação, todos com implicações na análise dos eventuais impactos da adoção dos sistemas privados de ensino pelos municípios.

Passamos à análise do conteúdo de cada uma dessas características, tomando como base as proposições que buscam integrar essa perspectiva internacional ao direito educacional brasileiro, com destaque para a interpretação proposta em Ximenes (2014).

A disponibilidade assim pode ser apresentada:

No nível mais imediato se encontra a própria existência de escolas em quantidade e condições suficientes para o desenvolvimento do processo educacional, ou seja, a disponibilidade de vagas, já que "a primeira obrigação do Estado é assegurar que existam escolas" (TOMASEVSKI, 2001, p.13). Como destaca esta autora, no regime internacional, a obrigação de disponibilidade compreende duas vertentes: os deveres de respeito e de proteção ao direito dos atores não estatais de estabelecer instituições educacionais e, principalmente, a obrigação estatal de realização consistente em estabelecer e/ou financiar a disponibilização de acesso a todos, segundo o regime de cada país (XIMENES, 2014, p. 247). 
A Constituição brasileira estipula uma faixa de escolaridade obrigatória, na qual é compulsória a frequência com o objetivo de universalização do acesso. Ressalte-se que, em relação à redação original desses dispositivos sobre obrigatoriedade, houve um processo de expansão da delimitação inicial dos deveres estatais, por força de Emendas Constitucionais. Essas emendas alteraram, substancialmente, o regime inicial, que estava mais próximo das balizas internacionais estabelecidas no Pacto de 1966.

Assim, hoje, é obrigatória a faixa de escolaridade compreendida entre quatro e dezessete anos de idade (CF/88, art. 208, I), o que envolve a pré-escola, o ensino fundamental e o ensino médio, nesse caso até que o adolescente venha a completar dezoito anos, já que a obrigatoriedade se vincula à idade e não à etapa escolar. Fora da faixa etária de escolaridade obrigatória - ensino médio comum após os 18 (dezoito) anos e, principalmente, educação infantil em creches (0 a 3 anos de idade) - o princípio reitor não é a universalização, mas a generalização do acesso a todos que manifestem o interesse em frequentar escola ou creche, ou seja, a generalização do acesso a toda a demanda. Essa diferença de regime quanto à disponibilidade, entretanto, não afeta a natureza do dever estatal de atendimento, conforme demonstrado por Ximenes (2014).

Conforme explana Ximenes (2014), nas etapas escolares e idades protegidas pelo regime da generalização, ou seja, nas etapas de escolaridade não obrigatória, as vagas escolares devem ser disponibilizadas e tornadas acessíveis, sem discriminação, a todos que, facultativamente, manifestem interesse em exercitar sua prerrogativa jurídica de acesso. No caso da educação infantil em creche, por força da interpretação jurisprudencial, já se consolidou a noção de que deve esta ser protegida como um direito público subjetivo, ainda que assim não esteja expresso no $\S 1^{\circ}$ do art. 208 da Constituição e em seu similar no ECA (art. 54, § $1^{\circ}$ ) (BRASIL, 1990).

Uma breve análise sobre as taxas de frequência à educação básica, obrigatória ou não obrigatória, seria suficiente para demonstrar que há um enorme déficit a ser enfrentado em face da delimitação atual dos deveres estatais quanto à disponibilidade.

Retomemos a análise sobre a acessibilidade, na obra de referência já apontada:

A acessibilidade, portanto, é o segundo nível de realização do direito à educação no esquema ora apresentado. Ela assegura um primeiro passo na superação da realização meramente formal desse direito. As dimensões da acessibilidade envolvem, inicialmente, os aspectos físicos, ou seja, a distância entre as instituições escolares e a residência dos estudantes, as condições de transporte até a escola, as condições de seu entorno relativas à segurança e à salubridade e as condições físicas de acesso às pessoas com deficiência ou mobilidade reduzida. Por fim, há o aspecto da acessibilidade econômica (XIMENES, 2014, p. 247).

O ECA inova, sob esse aspecto, ao estipular como direito dos estudantes o acesso à escola pública e gratuita próxima de sua residência (art. 53, V). Também reconhece o dever de gratuidade, tanto ao vedar que se condicione o acesso ao pagamento de taxas como ao estipular o dever de gratuidade ativa, através de programas suplementares de material 
didático-escolar, transporte, alimentação e assistência à saúde (art. 54, VII). Nesse sentido, enquanto componente geral do direito à educação, a acessibilidade econômica deve ser compreendida em sentido mais amplo. Essa característica, também se refere ao "que José Carlos de Araújo Melchior (1997) denominou como 'gratuidade ativa', em contraponto à visão restrita de gratuidade como mera exigência de acesso à escola sem pagamento" (XIMENES, 2014, p. 248). É nesse sentido que se defende o reconhecimento do dever estatal de fornecer material didático, vestuário, alimentação, transporte e assistência médica, odontológica e hospitalar a todos os estudantes da escola pública. Vejamos:

Além dos aspectos físicos e econômicos, a acessibilidade possui uma terceira dimensão: não discriminação. Ou seja, ainda que hipoteticamente estejam disponíveis escolas em quantidade suficiente, que estas sejam acessíveis fisicamente a todos, que sejam gratuitas - e, mais que isso, que existam nelas programas de apoio (gratuidade ativa) aos estudantes, com o fornecimento gratuito de transporte, uniforme (ou fardamento), material didático e alimentação escolar, e também de apoio às suas famílias, como a garantia de rendimento mensal básico associado à frequência à escola -, ainda assim é possível que um determinado grupo ou segmento de estudantes seja sistematicamente impedido de acessar a escola ou de fazê-lo em igualdade de condições (XIMENES, 2014, p. 249).

A não atenção ao requisito de não discriminação, portanto, viola o disposto no inciso I do art. 206 da Constituição, bem como a normativa internacional que detalha esse conteúdo. Trata-se, esse princípio, de uma norma imediata e universalmente aplicável, já que na interpretação do Comitê DESC "aplica-se plena e imediatamente a todos os aspectos da educação e contempla todos os motivos de discriminação proibidos internacionalmente" (ONU, 1999 apud XIMENES, 2014, p. 249).

A principal referência normativa internacional em matéria de não discriminação na educação, como atesta o Comitê, é a Convenção da UNESCO relativa à Luta contra as Discriminações no Campo do Ensino, de 1960. Essa Convenção traz aportes essenciais para o monitoramento da realização do direito à educação, razão pela qual destacamos o seu conteúdo neste trabalho:

É da Convenção da UNESCO de 1960 que o Comitê DESC extrai as definições sobre a discriminação na educação. Essa Convenção diferencia as discriminações proibidas [privar determinados grupos de acesso ao ensino ou oferecer-lhes educação escolar de mais baixa qualidade, principalmente] daquelas medidas de diferenciação que são autorizadas no regime de implementação do direito à educação [como políticas de ação afirmativa].

(...)

O dever estatal de eliminar e prevenir todas as modalidades de discriminação proibida (Convenção, art. $3^{\circ}$ ), portanto, significa tanto ab-rogar normas e institutos que promovam diretamente a discriminação na oferta de ensino e na distribuição desigual de oportunidades de aprendizagem, quanto desenvolver ações capazes de enfrentar o efeito discriminatório prático ou velado dos sistemas de ensino. (XIMENES, 2014, p. 249-250). 
Ou seja, a não-discriminação não deve se limitar aos aspectos jurídico-formais. Ainda que nesse primeiro plano seja assegurada disponibilidade e acessibilidade a todos, os Estados também devem "supervisionar cuidadosamente o ensino, compreendidas as correspondentes políticas, instituições, programas, pautas de gasto e demais práticas, a fim de explicitar qualquer discriminação de fato e adotar as medidas para saná-las" (ONU, 1999). Aprofundando esse conteúdo central do direito humano à educação:

A não discriminação, portanto, enquanto componente do direito à educação, envolve tanto obrigações negativas como positivas dos Estados. Requer a não edição ou manutenção de normas e institutos discriminatórios, mas também a realização de medidas voltadas a eliminar as discriminações de fato. Esse é o âmbito, por exemplo, no qual se apoiam as políticas de ação afirmativa no acesso à educação superior no Brasil. Requer também que se estabeleçam mecanismos permanentes de monitoramento sobre os impactos da política e do direito educacional, como forma de controlar eventuais efeitos discriminatórios.

Além de vedar as discriminações fundadas na exclusão ou no atendimento deficitário de determinados grupos ou segmentos específicos, a Convenção estabelece critérios para a aplicação do princípio da igualdade na educação. Para tanto, inclui no conceito de discriminação as distinções, exclusões, limitações ou preferências baseadas na condição econômica ou no nascimento, reconhecendo assim a discriminação econômica e a discriminação por nascimento no campo educacional. Assim, ocorrerão tais discriminações sempre que for limitada a igualdade de tratamento no acesso à escola ou for reduzida a nível inferior a educação que recebem determinados grupos econômicos ou regionais.

Portanto, ocorrerá discriminação econômica no acesso à educação sempre que as diferenças de renda sejam determinantes na definição das oportunidades de acesso ao ensino, ou quando refletirem diferentes níveis de qualidade em que é subministrado. Esse aspecto deve ser tomado como critério no monitoramento da situação da educação no País, principalmente na análise da relação entre renda, segmentação social e qualidade educativa (XIMENES, 2014, p. 251).

Vale destacar que uma parcela do negócio que caracteriza venda dos sistemas privados de ensino às redes públicas municipais tem como fundamento a promessa de levar às escolas públicas os mesmos materiais ou a mesma qualidade das escolas privadas que atendem à elite socioeconômica. As quais, no Brasil, em grande medida, devem seu desempenho acadêmico superior - quando comparadas às públicas em testes padronizados - tanto à seletividade econômica como à aplicação de provas para o ingresso.

Vale ressaltar que a Convenção de 1960 dá um lugar específico às escolas privadas, assim como a normativa internacional. Respeita, portanto, a liberdade de ensino quanto à criação de escolas privadas, com a condição que tais escolas não tenham como objetivo excluir determinados grupos, mas, tão somente, aumentar a disponibilidade e a diversidade de oferta de educação, e desde que respeitados os padrões estabelecidos pelo Estado (UNESCO, 2003).

No caso brasileiro, em geral as escolas privadas voltadas à elite têm como propósito e resultado a exclusão econômica dos segmentos populares, como forma de produzir vantagem Educação: Teoria e Prática/ Rio Claro/ Vol. 25, n.50/ p. 576-592/ Set.-Dez. 2015. 
educacional no acesso às universidades públicas e aos demais postos cobiçados no setor público e na iniciativa privada. Sugere-se que, justamente esse desempenho baseado em segmentação social legitimou a ampliação do negócio de algumas redes de escolas privadas (Objetivo, COC, Positivo etc.), rumo ao desenvolvimento dos sistemas privados apostilados que seriam, posteriormente, ofertados às redes públicas ${ }^{3}$.

$\mathrm{Na}$ educação obrigatória, as escolas privadas podem ser compreendidas como meios de discriminação estrutural na realização do direito à educação, já que as altas mensalidades cobradas funcionam como um forte mecanismo de seletividade social, que fortalece e reproduz as profundas desigualdades sociais, econômicas e etnicorraciais do Brasil. $\mathrm{Na}$ prática, ainda que mais recentemente essa realidade venha sendo parcialmente mitigada pelas políticas de ação afirmativa, frequentar escolas privadas tornou-se requisito para acessar os principais postos de trabalho e posições sociais. A não discriminação, portanto, está diretamente relacionada à exigência constitucional de garantia de educação de qualidade para todos.

Quanto à aceitabilidade, esta característica pode assim ser resumida:

[...] ainda que a educação esteja disponível e acessível a todos, sem discriminação de nenhum tipo, a realização do direito à educação depende da caracterização da oferta como aceitável do ponto de vista dos conteúdos, currículos, métodos e processos pedagógicos, e como relevante para o estudante e, em alguma medida, para os seus pais. A aceitabilidade demanda, ainda, que no ensino se busque realizar os objetivos amplos da educação e que sejam respeitados os padrões mínimos estabelecidos pelo próprio Estado em observância a tais objetivos.

A aceitabilidade é, portanto, a característica imediatamente relacionada à qualidade da educação em seu sentido amplo. A educação de qualidade, nesse sentido, é a educação aceitável na composição entre os interesses de crianças e pais e os objetivos públicos do ensino (XIMENES, 2014, p. 253).

Devem ser destacados, como critério de aceitabilidade, os objetivos amplos da educação, também estipulados nos tratados de direitos humanos e em documentos como o Comentário Geral n 1, de 2001 (ONU, 2001), sobre os objetivos da educação, do Comitê dos Direitos da Criança.

A aceitabilidade diz respeito tanto à infraestrutura física das escolas quanto aos conteúdos, processos e resultados educacionais. A noção de aceitabilidade, por fim, dialoga com a proposição normativa que defende a garantia de um padrão básico [aceitável] de qualidade para todos, que venha a obrigar o Estado, diretamente no exercício de seu dever de

\footnotetext{
${ }^{3}$ A Convenção de 1960 também veda a discriminação por nascimento, questão da mais alta relevância em um país economicamente desigual e assimetricamente federativo como o Brasil. Nesse sentido, a reprodução de desigualdades através da política de financiamento, como demonstram os estudos sobre o tema (ARAÚJO, 2013), devem ser entendidas como discriminação à luz dessa norma, já que o arranjo federativo não pode ser invocado como argumento válido para a preservação de condições tão diferentes no acesso a direitos fundamentais e, principalmente, não pode justificar a manutenção de condições de qualidade abaixo do nível aceitável. É nesse mesmo sentido que se posiciona o Comitê DESC: “Artigo 35. As agudas disparidades nas políticas de gasto que tenham como resultado que a qualidade da educação seja distinta para as pessoas que residem em diferentes lugares podem constituir uma discriminação com base no Pacto" (ONU, 1999).
} 
prestação, e indiretamente através da regulação e da fiscalização da oferta educacional privada, necessária à proteção dos direitos educacionais.

Há uma forte conexão entre a aceitabilidade e os deveres estatais de respeito e de proteção. Ao incorporar as dimensões de liberdade ao direito à educação, por exemplo, o ECA estipula que a aceitabilidade da educação escolar deverá ser construída em diálogo com os estudantes, os pais e os responsáveis. Aqueles, têm o direito de contestar critérios avaliativos e de recorrer às instâncias escolares superiores, enquanto estes têm o direito de ter ciência do processo pedagógico, bem como de participar da definição das propostas educacionais (ECA, art. 53, III e parágrafo único, respectivamente) (BRASIL, 1990).

Nesse ponto, a definição participativa da educação aceitável conecta-se ao próximo componente do direito à educação: a adaptabilidade, já que ambos estipulam requisitos procedimentais para a definição do conteúdo e da prática escolar e também espaços de autonomia que devem ser respeitados e protegidos pelo Estado. Conecta-se, também, ao princípio da gestão democrática do ensino público, princípio constitucional que tem, em seu âmbito de proteção, tanto o direito à participação de estudantes e demais membros da comunidade escolar e local na gestão das escolas e, em sentido geral, na gestão do sistema educacional, através de conselhos, conferências, fóruns e outros órgãos colegiados e instituições representativas autônomas (Lei n ${ }^{\circ} 13.005 / 2014$, arts. $5^{\circ}, 6^{\circ}$ e $9^{\circ}$ ) (BRASIL, 2014); como o direito específico de professores e pais a participar na definição do projeto pedagógico das escolas, como deixam evidenciados os dispositivos do ECA, já mencionados, além do art. 14 da LDB 9.394/1996 (BRASIL, 1996).

No caso do direito à participação de pais e estudantes, vale ressaltar que o ECA tem a importância de extrapolar esse direito para além do âmbito de proteção do princípio constitucional da gestão democrática, já que o direito à participação previsto nessa Lei é aplicável a todas as escolas, públicas ou privadas.

Por derradeiro, a adaptabilidade refere-se ao

[...] último nível de realização do direito à educação estipulado pelo Comitê DESC a partir da proposição de Tomasevski (2001), qualifica os demais em termos materiais e procedimentais, aproximando as características desse direito às necessidades específicas e diversas de comunidades, grupos, estudantes, familiares e educadores. Ou seja, ainda que a educação escolar seja disponibilizada e acessível sem discriminação a todos e que seja aceitável do ponto de vista de sua qualidade, o direito à educação deve ser também adaptável às exigências de diversidade, pluralismo e participação. É à adaptabilidade, portanto, que se conectam mais fortemente os princípios da liberdade, da diversidade e do pluralismo no ensino (CF/88, art. 206, II e III). É essa característica que impede que a garantia de um padrão de qualidade educacional, em si uma exigência jurídico-constitucional, venha a se converter em uniformização dos aspectos relacionados a essa qualidade, como insumos, conteúdos, processos e resultados.

A adaptabilidade é, assim, o ponto de equilíbrio a ser buscado na configuração do direito à qualidade do ensino, que deve almejar a igualdade enquanto respeita, protege e promove a diversidade. O primeiro sujeito a ser beneficiado pela adaptabilidade é o estudante. Como destaca Tomasevski (2001), no qual as características do direito à educação foram difundidas internacionalmente, os princípios da Convenção sobre os Direitos da Criança

Educação: Teoria e Prática/ Rio Claro/ Vol. 25, n.50/ p. 576-592/ Set.-Dez. 2015. 
apontam uma inversão radical de perspectiva: a escola deveria deixar de se preocupar em adaptar os estudantes para a vida adulta e passar a se adaptar às demandas dos estudantes enquanto crianças, adolescentes e jovens em desenvolvimento (XIMENES, 2014, p. 253-254).

É esse componente que se encontra especialmente protegido nos arts. 57 e 58 do ECA. No primeiro, estipula-se o dever de promoção de "pesquisas, experiências e novas propostas relativas a calendário, seriação, currículo, metodologia, didática e avaliação", com o objetivo de adaptar a oferta escolar às exigências de inserção de crianças e adolescentes excluídos do ensino. Já o art. 58, determina que "no processo educacional respeitar-se-ão os valores culturais, artísticos e históricos próprios do contexto social da criança e do adolescente, garantindo-se a estes a liberdade da criação e o acesso às fontes de cultura" (BRASIL, 1990).

Tal dispositivo não pode ser compreendido como uma mera diretriz, mas, sim, como requisito necessário à realização do direito à educação. Comporta tanto obrigações estatais positivas, voltadas a possibilitar a participação efetiva e a adaptação curricular, como obrigações de respeito e proteção (negativas), já que deve ser preservada a autonomia relativa de escolas e docentes no processo educacional. Daí se conclui:

Quando mencionamos o aspecto procedimental da adaptabilidade, nesse contexto, queremos destacar que tal característica, além de materialmente constitutiva do direito à educação nos termos, impõe que a definição de conteúdos, métodos, processos e resultados educacionais levem em conta a participação dos estudantes e dos demais atores sociais, respeitando-se o princípio da gestão democrática do ensino na Constituição de 1988.

As características aceitabilidade e adaptabilidade conectam o direito humano à educação aos direitos humanos na educação e através da educação. Só poderão ser consideradas aceitáveis as práticas e políticas educacionais que respeitem os direitos e liberdades no ensino e que tenham como resultado o fortalecimento da cidadania e dos direitos humanos. Ao mesmo tempo, só respeitam a cidadania, o pluralismo e os direitos humanos na e através da educação as práticas e políticas educacionais que reservam espaços para a adaptabilidade, a partir da participação direta de todos os atores envolvidos no processo educacional. (XIMENES, 2014, p. 254).

Passemos, no próximo tópico, à análise dos principais pontos de tensão entre o direito à educação, compreendido nos termos acima, e a adoção de sistemas privados apostilados de ensino pelas redes públicas municipais, prática que vem se disseminando no País.

\section{Privatização e hipóteses de violação das diferentes características do direito humano à educação}


Apresentado o conteúdo jurídico amplo do direito humano à educação, de forma integrada ao seu reconhecimento no direito brasileiro, passamos, agora, a apontar algumas hipóteses iniciais sobre como os processos de privatização da educação básica podem ameaçar esse direito, com ênfase nos resultados da crescente adoção de sistemas privados de ensino pelas redes públicas. Essas reflexões iniciais foram desenvolvidas no âmbito da pesquisa Sistemas de ensino privado na educação pública brasileira - consequências da mercantilização para o direito à educação ${ }^{4}$. Conforme já destacado, trata-se de estabelecer hipóteses para análises empíricas que venham a dimensionar e caracterizar as eventuais violações a esse direito.

Em relação à disponibilidade, a hipótese mais direta é que a crescente aplicação de recursos públicos na compra de sistemas privados padronizados, aliada ao significativo lucro obtido na venda de tais serviços às redes públicas, reduz a capacidade de o Estado disponibilizar novas vagas no sistema público, devido à redução dos recursos públicos disponíveis para a criação de novas oportunidades. Esse fator tende a impactar mais fortemente as etapas não obrigatórias (creche e educação básica para maiores de dezoito anos) ou as modalidades específicas, trazendo maiores prejuízos para as populações mais pobres, as crianças e adolescentes do campo, quilombolas e indígenas, os jovens e adultos com baixa escolaridade e as crianças e adolescentes com deficiência ou com necessidades educativas especiais. Nesse caso, será necessário estipular o valor que os governos dispendem com a compra de tais bens e serviços, em comparação com os valores aplicados em investimentos para a ampliação e qualificação das redes públicas.

Uma vez que os sistemas privados de ensino concorrem diretamente com o Programa Nacional do Livro Didático (PNLD), gerando o que a literatura vem denominando como um duplo gasto, sua adoção leva os municípios a abrirem mão ou subutilizarem importantes recursos que são fornecidos pela União.

Quanto à acessibilidade, o ponto crítico é o efeito discriminatório geral produzido pelas escolas privadas de elite. Tomando como referência o conteúdo do direito humano à educação, como visto, as escolas privadas podem ser compreendidas como meios de discriminação estrutural na realização desse direito, já que as altas mensalidades cobradas funcionam como um forte mecanismo de seletividade social, que fortalece e reproduz as profundas desigualdades sociais, econômicas, etnicorraciais do Brasil. Na prática, em muitos casos, a frequência às escolas privadas é requisito para acessar os principais postos de trabalho e posições sociais, aspecto que, apesar de naturalizado na realidade brasileira, viola conteúdos básicos do direito à educação.

Também é crítico o estímulo estatal ao atendimento discriminatório de crianças e adolescentes com deficiência, em escolas exclusivas, e ao atendimento de baixo custo na educação infantil, campos nos quais as parcerias público-privadas tendem, de um lado, a estimular e a reproduzir desigualdades, e, de outro, a favorecer a expansão por meio da educação privada, esvaziando, gradativamente, a capacidade estatal quanto à mudança dessa

\footnotetext{
${ }^{4}$ Pesquisa interinstitucional desenvolvida por Grupo de Estudos e Pesquisas em Políticas Educacionais (GREPPE) e Ação Educativa, denominada "Sistemas de ensino privados na educação pública brasileira: consequências da mercantilização para o direito à educação" financiada pela Open Society Foundation.

Educação: Teoria e Prática/ Rio Claro/ Vol. 25, n.50/ p. 576-592/ Set.-Dez. 2015.
} 
realidade. Essa política, hoje, está juridificada nas exceções legais que asseguram o repasse de recursos do FUNDEB à iniciativa privada (ARAÚJO, 2013).

As isenções fiscais (financiamento indireto) e o repasse direto de recursos para a iniciativa privada, lucrativa e não lucrativa, inclusive com a possibilidade de contabilização desses dispêndios para efeito de cálculo do montante investido em relação ao PIB, assim, incentiva a privatização, enfraquece a capacidade do Estado de implementar diretamente o ensino e tende a diminuir a infraestrutura, equipes técnicas e de gestão do Estado para a oferta de uma educação pública de qualidade. Ameaça, portanto, seus deveres quanto à disponibilidade e à acessibilidade sem discriminação.

Além disso, principalmente na educação infantil e na educação especial, a privatização da oferta, incentivada pelo repasse de recursos públicos do Estado, apresenta riscos relevantes à liberdade de opinião, crença e culto na educação, uma vez que, em muitas situações concretas, a única alternativa disponibilizada pelo Estado para o atendimento é a matrícula em instituições confessionais.

Em relação à aceitabilidade, vemos que o aumento da participação do setor privado na oferta de educação básica se deve à disseminação de uma visão negativa da educação pública, fomentada, indiretamente, pelos governos federal e estaduais através da disseminação dos resultados das escolas em testes padronizados de aprendizagem, entendidos na política pública como único critério de qualidade. Tais testes são disseminados de forma descontextualizada em relação ao perfil socioeconômico dos estudantes e à diversidade cultural, étnica e racial das populações.

A hegemonia dessa visão reduzida de qualidade educativa, por sua vez, está na base da disseminação dos sistemas privados de ensino nas redes públicas. A concepção de qualidade veiculada na adoção dos sistemas padronizados tem como referência a marca das escolas privadas que representam, legitimadas nas políticas públicas de avaliação. É, portanto, autorreferenciada e apoiada em estratégias publicitárias, normalmente fundadas na marca publicitária de alguma rede de escolas privadas voltadas à população de maior renda.

Normalmente, não há consulta às comunidades escolares (conselhos escolares, conselhos municipais de educação ou outros órgãos) antes da adoção dos sistemas privados padronizados de ensino, que são impostos unilateralmente às escolas, e, também, é escasso o feedback de escolas e gestores educacionais em relação à adoção dos sistemas privados, assim, fere-se a liberdade de ensinar dos profissionais docentes.

Portanto, quanto à adaptabilidade, nossa hipótese é que a adoção dos sistemas privados padronizados de ensino nas escolas públicas reduz, drasticamente, o espaço de adaptação curricular, bem como a autonomia pedagógica de escolas e professores, uma vez que todas as aulas, atividades e conteúdos passam a ser, em alguma medida, estandardizados.

Os sistemas privados padronizados adotados nas escolas públicas, com isso, tendem a submeter escolas, professores e estudantes à homogeneização e ao enfraquecimento de suas capacidades enquanto sujeitos ativos e criadores na realização do direito à educação. Nesse sentido, opõem-se, também, à gestão democrática da educação.

Por fim, para grupos historicamente marginalizados em seu direito à educação, a falta de regulamentação e de fiscalização dos sistemas privados padronizados, adotados nas escolas Educação: Teoria e Prática/ Rio Claro/ Vol. 25, n.50/ p. 576-592/ Set.-Dez. 2015. 
públicas, faz com que não haja garantias de que crianças com deficiência ou necessidades especiais, crianças campesinas, comunidades indígenas e quilombolas e demais populações tradicionais tenham respeitados os seus direitos à educação adaptada.

\section{Conclusão}

Vimos, portanto, que a definição ampla sobre o direito humano à educação, desenvolvida principalmente pelo Comitê de Direitos Econômicos, Sociais e Culturais da ONU, aliada a um enfoque metodológico que estabelece a necessária diferença entre o Direito em sua dogmática normativa e o fenômeno jurídico que se apresenta nos diferentes contextos, abre uma nova perspectiva para a análise jurídica da questão da privatização da educação no Brasil.

De um lado, supera-se a perspectiva formalista que tende a reduzir o Direito à sua expressão legal, ou seja, o conteúdo dos direitos fundamentais às regras jurídicas objetivas e positivas. De outro, permite analisar os impactos da privatização sobre aspectos mais amplos do direito em questão, como a aceitabilidade e a adaptabilidade, ou ainda suas graves implicações sobre dimensões essenciais como a liberdade de ensinar e de aprender, a autonomia relativa de escolas e professores e a gestão democrática da educação.

As hipóteses iniciais, levantadas no último tópico, tiveram como propósito estimular essa reflexão prática, ainda que para sua construção tenham sido levadas em conta pesquisas desenvolvidas sobre as parcerias público-privadas e a adoção de sistemas privados de ensino nas redes públicas, bem como posições críticas à privatização, que emergem da sociedade civil organizada.

\section{Referências}

ABRAMOVICH, V.; COURTIS, C. Los derechos sociales como derechos exigibles. 2. ed. Madrid: Trotta, 2004.

ADRIÃO, T. et al. Uma modalidade peculiar de privatização da educação pública: a aquisição de "sistemas de ensino" por municípios paulistas. Educ. Soc., Campinas, v. 30, n.108, p.799818, Out. 2009.

ADRIÃO, T. et al. As parcerias entre prefeituras paulistas e o setor privado na política educacional: expressão de simbiose?. Educ. Soc., Campinas, v. 33, n.119, p. 533-549, abr.jun. 2012.

ALEXY, R. Teoria dos direitos fundamentais. São Paulo: Malheiros, 2008.

ARAUJO, L. Limites e possibilidades da redução das desigualdades territoriais por meio do financiamento da educação básica. Depósito em 2013. 416 f. Tese (Doutorado em Educação) - Universidade de São Paulo, São Paulo, 2013. 
BRASIL. Constituição Federal, promulgada em 5 de outubro de 1988. Brasília: Casa Civil, 2014. Disponível em: http://www.planalto.gov.br/ccivil_03/Constituicao/Constituicao.htm. Acesso em: 20 dez. 2015.

BRASIL. Lei 8.069, de 13 de julho de 1990. Dispõe sobre o Estatuto da Criança e do Adolescente e dá outras providências. Brasília: Casa Civil, 2014. Disponível em: http://www.planalto.gov.br/ccivil_03/LEIS/L8069.htm. Acesso em: 20 dez. 2015.

BRASIL. Lei 9.394, de 20 de dezembro de 1996. Estabelece as diretrizes e bases da Educação Nacional. Brasília: Casa Civil, 1996. Disponível em:

<http://www.planalto.gov.br/ccivil_03/Leis/L9394.htm>. Acesso em: 20 dez. 2015.

BRASIL. Lei no 13.005, de 25 junho de 2014. Aprova o Plano Nacional de Educação - PNE e dá outras providências. Brasília: Casa Civil, 2014. Disponível em:

http://www.planalto.gov.br/ccivil_03/_ato2011-2014/2014/lei/113005.htm. Acesso em: 20 dez. 2015.

NEVES, M. A constitucionalização simbólica. São Paulo: Martins Fontes, 2011.

ORGANIZAÇÃO DAS NAÇÕES UNIDAS - ONU. Comitê de Direitos Econômicos, Sociais e Culturas. Recomendações Gerais. ONU: Comitê Desc, 1999. Disponível em:

<http://www.ohchr.org/en/hrbodies/cescr/pages/cescrindex.aspx >. Acesso em: 12 fev. 2015.

ORGANIZAÇÃO DAS NAÇÕES UNIDAS - ONU. Comitê dos Direitos da Criança.

Comentários Gerais. Lisboa: Gabinete de Documentação e Direito Comparado, 2001.

Disponível em: <http://direitoshumanos.gddc.pt/2_1/IIPAG2_1_2_6_2.htm >. Acesso em: 12 fev. 2015.

ORGANIZAÇÃO DAS NAÇÕES UNIDAS PARA A EDUCAÇÃO, A CIÊNCIA E A CULTURA - UNESCO. Convenção relativa à Luta contra a Discriminação no campo do Ensino. Adotada a 14 de dezembro de 1960, pela Conferência Geral da UNESCO, em sua 11 ${ }^{\text {a }}$ sessão, reunida em Paris de 14 de novembro a 15 de dezembro de 1960. Brasília: UNESCO, 2003. Disponível em: http://unesdoc.unesco.org/images/0013/001325/132598por.pdf. Acesso em: 20 dez. 2015.

XIMENES, S. B. Direito à Qualidade na Educação Básica: teoria e crítica. São Paulo: Quartier Latin, 2014.

TOMASEVSKI, K. Human Rights Obligations in Education: the 4-A scheme. Nijmegen: Wolf Legal Publishers, 2006.

Recebido em: 22/05/2015

Revisado em: 08/12/2015 
Aprovado para publicação em: 21/12/2015

Publicado em: 22/12/2015

Educação: Teoria e Prática/ Rio Claro/ Vol. 25, n.50/ p. 576-592/ Set.-Dez. 2015. 